\title{
Improving thermal stability of hard coating films via a concept of multicomponent alloying
}

Hans Lind, Rikard Forsén, Björn Alling, Naureen Ghafoor, Ferenc Tasnadi, M P Johansson, Igor Abrikosov and Magnus Odén

\section{Linköping University Post Print}

N.B.: When citing this work, cite the original article.

Original Publication:

Hans Lind, Rikard Forsén, Björn Alling, Naureen Ghafoor, Ferenc Tasnadi, M P Johansson, Igor Abrikosov and Magnus Odén, Improving thermal stability of hard coating films via a concept of multicomponent alloying, 2011, Applied Physics Letters, (99), 9, 091903.

http://dx.doi.org/10.1063/1.3631672

Copyright: American Institute of Physics (AIP) http://www.aip.org/

Postprint available at: Linköping University Electronic Press

http://urn.kb.se/resolve?urn=urn:nbn:se:liu:diva-70747 


\title{
Improving thermal stability of hard coating films via a concept of multicomponent alloying
}

\author{
H. Lind, ${ }^{\text {a) }}$ R. Forsén, B. Alling, N. Ghafoor, F. Tasnádi, M. P. Johansson, \\ I. A. Abrikosov, and M. Odén \\ Department of Physics, Chemistry and Biology (IFM), Linköping University, Linköping SE-581 83, Sweden
}

(Received 15 June 2011; accepted 8 August 2011; published online 29 August 2011)

\begin{abstract}
We propose a design route for the next generation of nitride alloys via a concept of multicomponent alloying based on self-organization on the nanoscale via a formation of metastable intermediate products during the spinodal decomposition. We predict theoretically and demonstrate experimentally that quasi-ternary $(\mathrm{TiCrAl}) \mathrm{N}$ alloys decompose spinodally into (TiCr) $\mathrm{N}$ and $(\mathrm{CrAl}) \mathrm{N}$-rich nanometer sized regions. The spinodal decomposition results in age hardening, while the presence of $\mathrm{Cr}$ within the AlN phase delays the formation of a detrimental wurtzite phase leading to a substantial improvement of thermal stability compared to the quasi-binary (TiAl)N or (CrAl)N alloys. (C) 2011 American Institute of Physics. [doi:10.1063/1.3631672]
\end{abstract}

To maximize the operation efficiency of the industrial high precision machining or cutting tools, materials with extended lifetime, increased hardness and improved thermal stability are demanded. In particular, alloying of $\mathrm{TiN}$ or $\mathrm{CrN}$ with AlN is known to improve the performance of these nitrides as a wear protection coating in metal cutting applications as compared to $\mathrm{TiN}$ or $\mathrm{CrN}$ compounds. ${ }^{1-4}$ In (TiAl)N, the alloying leads to the increased oxidation resistance and improved high temperature mechanical properties. The latter originates from an age hardening phenomenon, arising from the spinodal decomposition of (TiAl)N into coherent domains of AlN and TiN-enriched (TiAl)N with B1 crystal structure. ${ }^{5-8}$ An enhanced hardness of $(\mathrm{TiAl}) \mathrm{N}$ is observed after annealing to about $900{ }^{\circ} \mathrm{C}$ at which point a transformation of cubic AlN into the more stable wurtzite AlN phase, possibly in combination with relaxation of coherency stresses between remaining c-AlN and TiN domains, is believed to make the material considerably softer. This detrimental transformation from a cutting performance perspective limits the amount of $\mathrm{Al}$ in (TiAl)N coatings. On the other hand, a larger amount of $\mathrm{Al}$ can be solved in the B1 phase of $(\mathrm{CrAl}) \mathrm{N}$ alloy due to its ability to resist the formation of such a wurtzite phase up to higher Al content and higher temperatures. ${ }^{9}$ However, the spinodal decomposition is generally not observed in this system, and, therefore, an age hardening as seen in ( $\mathrm{TiAl}) \mathrm{N}$ is not observed.

In this letter, by means of theoretical simulations and experimental studies, we demonstrate that a concept of multicomponent alloying for nitride ceramics can lead to cumulative favorable effects resulting in a substantial improvement of coatings properties. We show a possibility to tailor, by alloying with a third component, the properties of metastable products of spinodal decomposition. We perform first-principle electronic structure and total energy calculations to analyze the local tendencies of spinodal decomposition in multicomponent cubic (TiCrAl)N alloys, and predict the formation of coherent cubic ( $\mathrm{TiCr}) \mathrm{N}$ and $(\mathrm{CrAl}) \mathrm{N}$ phases. The presence of $\mathrm{Cr}$ in the AlN-rich cubic domains is predicted to delay the onset of their

${ }^{\text {a)} E l e c t r o n i c ~ m a i l: ~ h a l i n @ i f m . l i u . s e . ~}$ transformation into the wurtzite phase, resulting in improved thermal stability of the multicomponent system as compared to quasi-binary alloys. We demonstrate experimentally that during the transformation few nanometer large, coherent stable cubic $(\mathrm{TiCr}) \mathrm{N}$ and metastable $(\mathrm{CrAl}) \mathrm{N}$ rich regions are formed indeed, and verify the extended thermal stability of the quasiternary $(\mathrm{TiCrAl}) \mathrm{N}$ alloy coating.

In order to develop a fundamental understanding of the proposed multicomponent alloying concept, we applied firstprinciples calculations on a quasi-ternary $c-\mathrm{Ti}_{x} \mathrm{Cr}_{y} \mathrm{Al}_{z} \mathrm{~N}$ system to determine its thermodynamic properties and the products of the possible phase decomposition. The density functional theory (DFT) calculations were performed using the Koringa-Kohn-Rostocker (KKR) method within the atomic sphere approximation (ASA) combined with the coherent potential approximation $(\mathrm{CPA})^{10}$ and the magnetic disorder amongst the $\mathrm{Cr}$ atoms was handled within the disordered local moment (DLM) approximation. ${ }^{11}$ We used a theoretical methodology developed in our previous works, $8,9,12$ where the phase stability and properties of the quasi-binary $\mathrm{Ti}_{1-x} \mathrm{Al}_{x} \mathrm{~N}, \mathrm{Cr}_{1-x} \mathrm{Al}_{x} \mathrm{~N}$ and $\mathrm{Ti}_{1-x} \mathrm{Cr}_{x} \mathrm{~N}$ systems were studied. For further details, see supplementary material. ${ }^{13}$ As we are mostly interested in the spinodal decomposition, we considered only the cubic $\mathrm{B} 1$ phase of $\mathrm{Ti}_{x} \mathrm{Cr}_{y} \mathrm{Al}_{z} \mathrm{~N}$, regardless of composition. Within this B1 structure, one of the fcc sublattices holds the $\mathrm{N}$ atoms and has no compositional disorder, while the other sublattice holds all the metal atoms and it is modeled as a completely random alloy. The phase stability of a random alloy as a function of concentration parameters $x, y$, and $z$ as well as temperature $T$ and pressure $p$ is determined by the Gibbs free energy $G(x, y, z, T)=E(x, y, z)$ $-T S(x, y, z)+p V$ where $E(x, y, z)$ is the energy, $V$ is the volume, and $S(x, y, z)$ is the entropy. Vibrational entropy, as well as pressure effects are not considered in this work, and the configurational entropy is treated within the mean-field approximation. ${ }^{8}$ The reliability of the latter has been established for the case of (TiAl)N by Alling et al. ${ }^{14}$ For spinodal decomposition to occur, it is required that the second directional derivative of $G(x, y, z)$ along at least one direction $v_{x, y, z}$ in the constrained composition plane is negative, 
$d^{2} G(x, y, z) / d v_{x, y, z}^{2}<0$. Once this condition is fulfilled any change in the composition along this line will result in an overall decrease in energy.

Fig. 1(a) shows the mixing free energy for $\mathrm{c}-\mathrm{Ti}_{x} \mathrm{Cr}_{y} \mathrm{Al}_{z} \mathrm{~N}$ relative to the cubic $\mathrm{B} 1$ phases of $\mathrm{TiN}, \mathrm{CrN}$, and $\mathrm{AlN}$ at 1300 $\mathrm{K}$. In comparison with the $0 \mathrm{~K}$ results (see supplementary material), where the mixing-free-energy is positive for all composition and suggest strong thermodynamic instability, the mixing energy at $1300 \mathrm{~K}$ decreases, as expected, to the extent that $(\mathrm{TiCr}) \mathrm{N}$ alloys become stable, while the decomposition trend is still present in $(\mathrm{CrAl}) \mathrm{N}$ and especially in (TiAl)N-rich alloys. Therefore, on the basis of thermodynamic stability arguments, we conclude that the binodal decomposition in ternary alloys should result in (TiCr)N-rich phase and c-AlN, where the latter should eventually transform into the wurtzite phase. The conclusion above is similar to the observations made in other quasi-ternary systems earlier. ${ }^{15-17}$

However, in this work, we are interested in knowing the spinodal decomposition behavior. Indeed, thin films of these alloys synthesized by physical vapor techniques can be grown in a highly non-equilibrium state. In particular, if diffusion is limited by growth at low temperatures, supersaturated solid solution alloys deep within the spinodal region

(a)

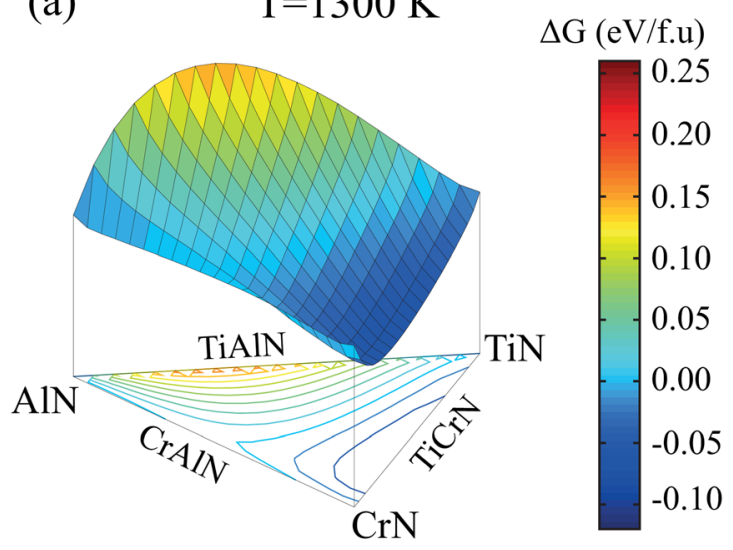

(b)

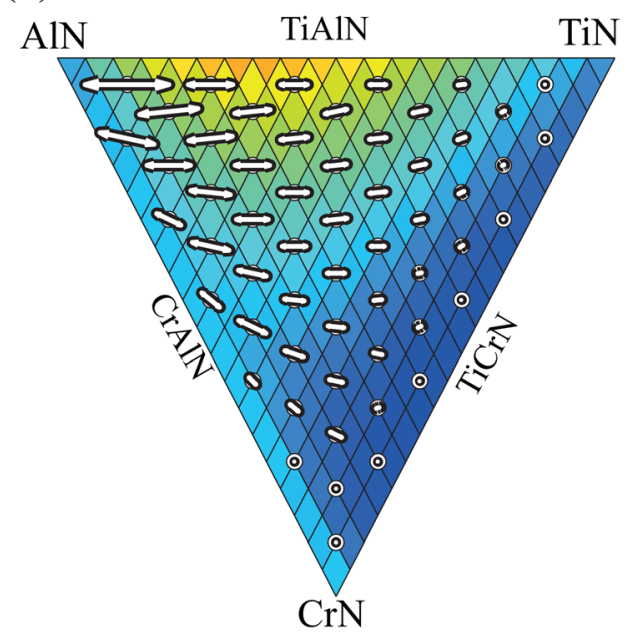

FIG. 1. (Color online) Calculated mixing free energy $\Delta G$ (a) and the local tendencies for the spinodal decomposition (b) in $\mathrm{c}-\mathrm{Ti}_{z} \mathrm{Cr}_{y} \mathrm{Al}_{x} \mathrm{~N}$ at $1300 \mathrm{~K}$. The arrows represent the most favorable directions of spinodal decomposition. The lengths of the arrows are proportional to the magnitudes of the second derivatives, indicating the strength of the decomposition trends. The circles represent compositions with positive second derivatives in all directions. can be realized. In such cases, due to absence of nucleation barriers, one should expect the onset of spinodal decomposition before the binodal transformation takes place. Below we show that this transformation can have different decomposition products, and as a matter of fact it can be beneficial rather than detrimental for the properties of the film.

Fig. 1(b) shows the most favorable paths of the spinodal decomposition for each concentration defined as the direction for which the second derivative of the Gibbs free energy attains the lowest negative value assuming that it is negative in at least some direction. The decomposition diagrams in Fig. 1(b) clearly show that for low to moderate amounts of $\mathrm{Cr}$ in the quasi-ternary alloys, the decomposition arrows point almost parallel to the TiN-AlN axis, suggesting that there is little to no separation of the $\mathrm{Cr}$ between the TiN and AlN-rich phases. The theory suggests that ( $\mathrm{TiCrAl}) \mathrm{N}$ alloys would decompose into a $(\mathrm{TiCr}) \mathrm{N}$ and a $(\mathrm{CrAl}) \mathrm{N}$ phase, which may be metastable, or even fully stable with respect to cubic phases, at higher temperatures. Of course, Fig. 1(b) only gives the locally most favorable directions of the spinodal decomposition and the corresponding arrows may not lead to the final products, but it does indicate decomposition towards an AlN phase mixed with a small amount of $\mathrm{Cr}$.

This observation should have an important consequence for the performance of films based on (TiCrAl)N alloys. Similar to (TiAl)N films, the spinodal decomposition takes place, but the presence of $\mathrm{Cr}$ in AlN-rich domains should counteract their transformation into the wurtzite phase, as in the case of (CrAl)N binary thin films. Furthermore, the presence of $\mathrm{Cr}$ in both the TiN- and AlN-rich domains decrease the difference in their equilibrium lattice spacing. Indeed our calculation show that the difference in lattice spacing between $\mathrm{Ti}_{0.85} \mathrm{Cr}_{0.15} \mathrm{~N}$ and c- $\mathrm{Al}_{0.85} \mathrm{Cr}_{0.15} \mathrm{~N}$ is $4.8 \%$ as compared to $5.9 \%$ between TiN and c-AlN. This is likely to result in a somewhat weaker impact of age hardening, but also a reduction of the driving force for relaxing the coherent domain boundaries. This could allow the stressed state to survive to higher temperatures.

To verify the theoretical prediction, we carried out the experimental study on as-deposited and annealed alloys of $\mathrm{Ti}_{0.45} \mathrm{Cr}_{0.08} \mathrm{Al}_{0.47} \mathrm{~N}$ and $\mathrm{Ti}_{0.31} \mathrm{Cr}_{0.07} \mathrm{Al}_{0.62} \mathrm{~N}$ for which elemental composition was determined by elastic recoil detection analysis and energy dispersive $\mathrm{x}$-ray spectroscopy (EDX). Fig. 2(a) shows a lattice resolved high resolution bright field transmission electron microscopy (TEM) image of the $\mathrm{Ti}_{0.45} \mathrm{Cr}_{0.08} \mathrm{Al}_{0.47} \mathrm{~N}$ composition that has been annealed at $1000^{\circ} \mathrm{C}$ for $2 \mathrm{~h}$ in Ar-atomsphere. The image and the corresponding diffraction pattern reveal a cubic and coherent lattice throughout the imaged area. The corresponding atomic number contrast scanning-TEM image in Figure 2(b) shows that the elements are not evenly distributed. The insets present maps based on results from an EDX scan recorded within the square (labeled 1). The maps show in accordance with the theoretical predictions that $\mathrm{Ti}$ (red) and $\mathrm{Al}$ (green) have segregated whereas $\mathrm{Cr}$ (blue) is nearly uniformly distributed across the sample with only a weak tendency for preferential location to Ti-rich domains. In Fig. 2(c), a $20 \mathrm{~nm}$ line scan shows that the wavelength of the segregation is approximately $5 \mathrm{~nm}$, indicating a self-organization at the nanometer scale. To elucidate the effect of the proposed multicomponent alloying on the thermal stability, we present in Fig. 3 results from differential scanning 

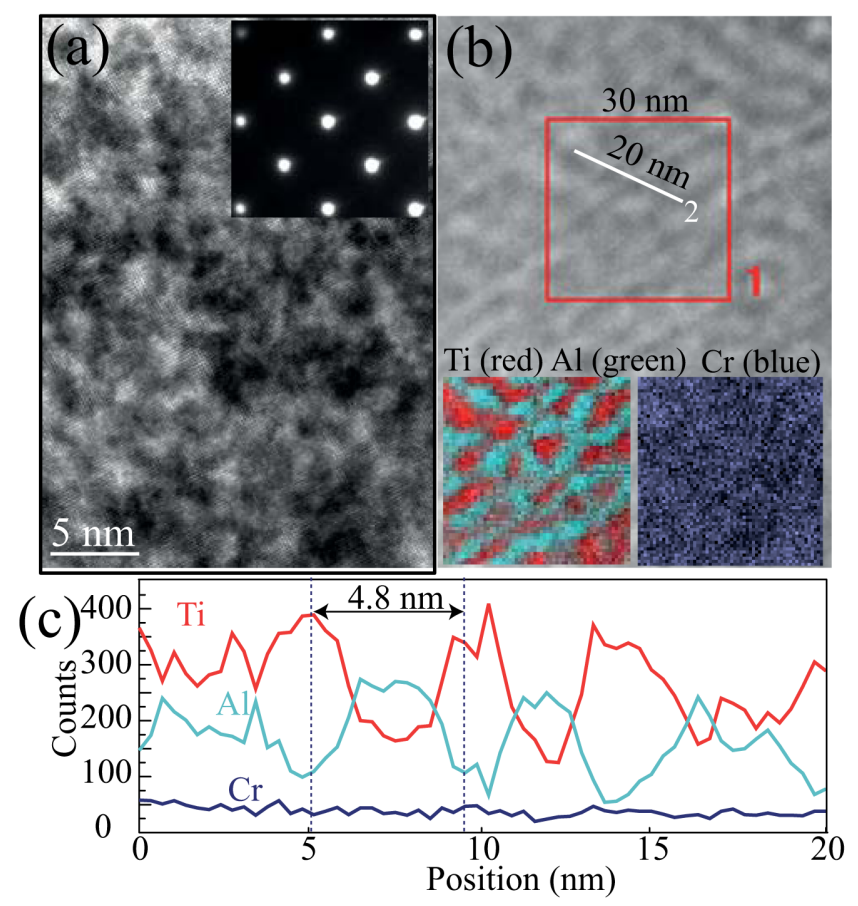

FIG. 2. (Color online) TEM analysis of $\mathrm{Ti}_{0.45} \mathrm{Cr}_{0.08} \mathrm{Al}_{0.47} \mathrm{~N}$ coating. (a) Lattice resolved diffraction contrast bf TEM image of a region aligned along the 002 zone axis and corresponding selected area electron diffraction (SAED). (b) Predominant $z$ contrast scanning-TEM image including $30 \times 30 \mathrm{~nm}^{2}$ area (red square \#1) scanned to record EDX map with $0.5 \mathrm{~nm} /$ pixel resolution. Overlaid color coded maps of $\mathrm{Ti}(\mathrm{red}), \mathrm{Cr}$ (blue), and $\mathrm{Al}$ (green) are shown in the insets. (c) The Ti, Cr, and $\mathrm{Al}$ signal extracted from a $20 \mathrm{~nm}$ EDX line profile (labeled 2 in image (b) recorded with $0.3 \mathrm{~nm} /$ pixel resolution.

calorimetry (DSC) measurements of $\mathrm{Ti}_{0.31} \mathrm{Cr}_{0.07} \mathrm{Al}_{0.62} \mathrm{~N}$ (red) together with previously reported data for $\mathrm{Ti}_{0.33} \mathrm{Al}_{0.67} \mathrm{~N}$ (blue). ${ }^{18}$ The samples were heated up to $1400^{\circ} \mathrm{C}$ at a rate of $20{ }^{\circ} \mathrm{C} \mathrm{min}{ }^{-1}$. The peak at $\sim 1100{ }^{\circ} \mathrm{C}$ for $\mathrm{Ti}_{0.33} \mathrm{Al}_{0.67} \mathrm{~N}$ has previously been identified as the position where c-AlN transforms into its hexagonal structure, which leads to a decrease of the hardness of the coating. ${ }^{18}$ The location of the peak at $\sim 1250{ }^{\circ} \mathrm{C}$ for $\mathrm{Ti}_{0.31} \mathrm{Cr}_{0.07} \mathrm{Al}_{0.62} \mathrm{~N}$ seen in Fig. 3 (red) suggests that the hexagonal transformation occurs at higher temperature than for $\mathrm{Ti}_{0.33} \mathrm{Al}_{0.67} \mathrm{~N}$. Consequently, the inset of the figure shows hardness results versus annealing temperature ( $2 \mathrm{~h}$ ) obtained by nanoindentation. For $\mathrm{Ti}_{0.33} \mathrm{Al}_{0.67} \mathrm{~N}$ alloy (blue), a maximum

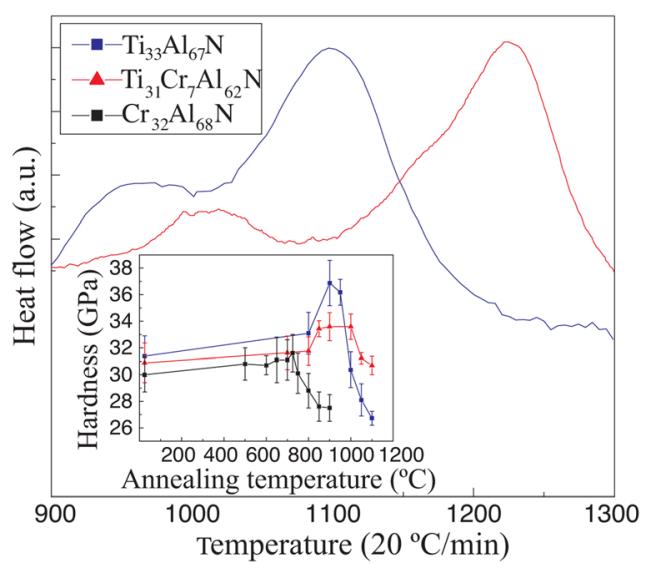

FIG. 3. (Color online) DSC results obtained from $\mathrm{Ti}_{0.31} \mathrm{Cr}_{0.07} \mathrm{Al}_{0.62} \mathrm{~N}$ and $\mathrm{Ti}_{0.33} \mathrm{Al}_{0.67} \mathrm{~N}$ showing the alleged hexagonal transformation peaks. The inset contains hardness results of $\mathrm{Ti}_{0.31} \mathrm{Cr}_{0.07} \mathrm{Al}_{0.62} \mathrm{~N}$ in comparison to $\mathrm{Ti}_{0.33} \mathrm{Al}_{0.67} \mathrm{~N}$ and $\mathrm{Cr}_{0.32} \mathrm{Al}_{0.68} \mathrm{~N}$. Samples were annealed at up to $1100^{\circ} \mathrm{C}$ for $2 \mathrm{~h}$. hardness is reached at about $900{ }^{\circ} \mathrm{C}$ and $\mathrm{Cr}_{0.32} \mathrm{Al}_{0.68} \mathrm{~N}$ (black) ${ }^{19}$ has a maximum at $725^{\circ} \mathrm{C}$ whereas $\mathrm{Ti}_{0.31} \mathrm{Cr}_{0.07} \mathrm{Al}_{0.62} \mathrm{~N}$ (red) retains its hardness up to $1000{ }^{\circ} \mathrm{C}$. Even though the magnitude of the hardening is slightly smaller in the Cr-containing film, it is the hardest coating at elevated temperatures.

In summary, we introduce a concept of how multicomponent alloying can be used for designing of the next generation of nitride alloys. The concept relies on having intermediate products during the spinodal decomposition that allow control of the thermal stability. We illustrate the concept by means of first-principle calculations on the quasiternary $\mathrm{Ti}_{x} \mathrm{Cr}_{y} \mathrm{Al}_{z} \mathrm{~N}$ and show that the $\mathrm{Cr}$-content can be used to tailor the thermal behavior of the material. In particular, we predict the formation of the intermediate metastable $(\mathrm{TiCr}) \mathrm{N}$ and $(\mathrm{CrAl}) \mathrm{N}$ products rather than $(\mathrm{TiCr}) \mathrm{N}$ and pure AlN as expected for a binodal decomposition. It enhances the thermal stability as the formation of $(\mathrm{CrAl}) \mathrm{N}$ postpones the detrimental formation of a wurtzite AlN-rich phase. We confirmed the theoretical prediction experimentally on post deposition annealed (TiCrAl)N thin films by showing formation of nm-sized cubic-( $\mathrm{TiCr}) \mathrm{N}$ and cubic-(CrAl)N phase domains. Concurrently, the transformation to wurtzite AlN and the age hardening process occur at higher temperatures compared to $(\mathrm{TiAl}) \mathrm{N}$ and $(\mathrm{CrAl}) \mathrm{N}$. An improved thermal stability is thus verified through $\mathrm{Cr}$ alloying of (TiAl)N.

This work was supported by the SSF-project Designed multicomponent coatings, MultiFilms and the Swedish Research Council. IAA is grateful to the Gran Gustafsson Foundation for Research in Natural Sciences and Medicine for the financial support. Calculations were carried out at the Swedish National Infrastructure for Computing (SNIC).

${ }^{1}$ A. Hörling, L. Hultman, M. Odén, J. Sjölén, and L. Karlsson, Surf. Coat. Technol. 191, 384 (2005).

${ }^{2}$ H. Hasegawa and T. Suzuki, Surf. Coat. Technol. 188, 234 (2004).

${ }^{3}$ H. Ljungcrantz, M. Odén, L. Hultman, J. E. Greene, and J. E. Sundgren, J. Appl. Phys. 80, 6725 (1996).

${ }^{4}$ D. Gall, C. S. Shin, T. Spila, M. Odén, M. J. H. Senna, J. E. Greene, and I. Petrov, J. Appl. Phys. 91, 3589 (2002).

${ }^{5}$ A. Hörling, L. Hultman, M. Odén, J. Sjölén, and L. Karlsson, J. Vac. Sci. Technol. 20, 1815 (2002).

${ }^{6}$ P. H. Mayrhofer, A. Hörling, L. Karlsson, J. Sjölén, T. Larsson, C. Mitterer, and L. Hultman, Appl. Phys. Lett. 83, 2049 (2003).

${ }^{7}$ A. Knutsson, M. P. Johansson, P. O. A. Persson, L. Hultman, and M. Odén, Appl. Phys. Lett. 93, 143110 (2008).

${ }^{8}$ B. Alling, A. V. Ruban, A. Karimi, O. Peil, L. Simak, S. I. Hultman, and I. A. Abrikosov, Phys. Rev. B 75, 045123 (2007).

${ }^{9}$ B. Alling, T. Marten, I. A. Abrikosov, and A. Karimi, J. Appl. Phys. 102, 044314 (2007).

${ }^{10}$ A. V. Ruban and I. A. Abrikosov, Rep. Prog. Phys. 71, 046501 (2008).

${ }^{11}$ B. L. Gyorffy, A. J. Pindor, J. Staunton, G. M. Stocks, and H. Winter, J. Phys. F 15, 1337 (1985).

${ }^{12}$ B. Alling, Phys. Rev. B 82, 054408 (2010).

${ }^{13}$ See supplementary material at http://dx.doi.org/10.1063/1.3631672 for the details of the ab-initio density functional calculations and $0 \mathrm{~K}$ results.

${ }^{14}$ B. Alling, V. A. Ruban, A. Karimi, L. Hultman, and I. A. Abrikosov, Phys. Rev. B 83, 104203 (2011).

${ }^{15}$ P. H. Mayrhofer, R. Rachbauer, and D. Holec, Scr. Mater. 63, 807 (2010).

${ }^{16}$ F. Rovere, D. Music, J. M. Schneider, and P. H. Mayrhofer, Acta Mater. 58, 2708 (2010).

${ }^{17}$ R. Rachbauer, D. Holec, and P. H. Mayrhofer, Appl. Phys. Lett. 97, 151901 (2010).

${ }^{18}$ A. Knutsson, M. P. Johansson, L. Karlsson, and M. Odén, J. Appl. Phys. 108, 044312 (2010).

${ }^{19}$ H. Willmann, P. H. Mayrhofer, L. Hultman, and C. Mitterer, J. Appl. Phys. 108, 044312 (2010). 